\title{
Inhibition of AMP-Activated Protein Kinase Signaling Alleviates Impairments in Hippocampal Synaptic Plasticity Induced by Amyloid $\beta$
}

\author{
Tao Ma, ${ }^{1}$ Yiran Chen, ${ }^{1}$ Valerie Vingtdeux, ${ }^{2}$ Haitian Zhao, ${ }^{2}$ Benoit Viollet,${ }^{3,4,5}$ Philippe Marambaud, ${ }^{2}$ and Eric Klann ${ }^{1}$ \\ ${ }^{1}$ Center for Neural Science, New York University, New York, New York 10003, ${ }^{2}$ Litwin-Zucker Research Center for the Study of Alzheimer's Disease, The \\ Feinstein Institute for Medical Research, Manhasset, New York 11030, ${ }^{3}$ Institut Cochin, INSERM U1016, Paris 75014, France, ${ }^{4}$ CNRS, UMR 8104, Paris \\ 75014, France, and ${ }^{5}$ Université Paris Descartes, Sorbonne Paris Cité, Paris 75014, France
}

The AMP-activated protein kinase (AMPK) is a Ser/Thr kinase that is activated in response to low-energy states to coordinate multiple signaling pathways to maintain cellular energy homeostasis. Dysregulation of AMPK signaling has been observed in Alzheimer's disease (AD), which is associated with abnormal neuronal energy metabolism. In the current study we tested the hypothesis that aberrant AMPK signaling underlies $\mathrm{AD}$-associated synaptic plasticity impairments by using pharmacological and genetic approaches. We found that amyloid $\beta(\mathrm{A} \beta$ )-induced inhibition of long-term potentiation (LTP) and enhancement of long-term depression were corrected by the AMPK inhibitor compound C (CC). Similarly, LTP impairments in APP/PS1 transgenic mice that model AD were improved by CC treatment. In addition, A $\beta$-induced LTP failure was prevented in mice with genetic deletion of the AMPK $\alpha 2$-subunit, the predominant AMPK catalytic subunit in the brain. Furthermore, we found that eukaryotic elongation factor 2 (eEF2) and its kinase eEF2K are key downstream effectors that mediate the detrimental effects of hyperactive AMPK in AD pathophysiology. Our findings describe a previously unrecognized role of aberrant AMPK signaling in AD-related synaptic pathophysiology and reveal a potential therapeutic target for AD.

Key words: Alzheimer's disease; long-term potentiation; neurodegeneration; protein synthesis; signaling; translation

\section{Introduction}

Alzheimer's disease (AD) incidence has been rising consistently with an aging population, potentially becoming a global threat to public health (Querfurth and LaFerla, 2010; Holtzman et al., 2011). Meanwhile, the lack of effective interventions for AD suggests that the development of therapeutics will require novel targets based on the identification of aberrant molecular mechanisms underlying $\mathrm{AD}$-related pathophysiology.

One of the signaling molecules that could be a therapeutic target for $\mathrm{AD}$ is the AMP-activated protein kinase (AMPK). Mammalian AMPKs are heterotrimeric complexes composed of

Received April 27, 2014; revised July 16, 2014; accepted Aug. 1, 2014.

Author contributions: T.M. and E.K. designed research; T.M., Y.C., V.V., H.Z., and B.V. performed research; V.V., B.V., and P.M. contributed unpublished reagents/analytic tools; T.M., Y.C., V.V., B.V., P.M., and E.K. analyzed data; T.M. and E.K. wrote the paper.

This work was supported by National Institutes of Health grants NS034007 and NS047834 and an Alzheimer's Association Investigator grant to E.K., National Institutes of Health Grant K99 AG044469 and a grant from the BrightFocus Foundation to T.M., and National Institutes of Health Grant R01AG042508 to P.M. We thank Dr. Peter Davies of The Feinstein Institute for Medical Research and the late Dr. Mark A. Smith of Case Western Reserve University for providing postmortem AD brain samples. We thank Maggie Dorsey for maintaining the mouse colonies.

The authors declare no competing financial interests.

Correspondence should be addressed to Dr. Eric Klann, 4 Washington Place, Room 809, Center for Neural Science, New York University, New York, NY 10003. E-mail: eklann@cns.nyu.edu.

T. Ma's present address: Department of Internal Medicine-Gerontology and Geriatric Medicine, Wake Forest University School of Medicine, Winston-Salem, NC 27157.

DOI:10.1523/JNEUROSCI.1694-14.2014

Copyright $\odot 2014$ the authors $\quad 0270-6474 / 14 / 3412230-09 \$ 15.00 / 0$ a catalytic $\alpha$-subunit encoded by either the $\alpha 1$ or $\alpha 2$ gene, and regulatory $\beta$ - and $\gamma$-subunits. AMPK is activated by either binding of AMP with the $\gamma$-subunit or phosphorylation of the $\alpha$-subunit at Thr172; the latter is quantitatively more important for enzymatic activity (Hardie, 2004). AMPK is a key regulator of cellular energy homeostasis, which is activated in response to low-energy states (Hardie et al., 2012), and AD has been linked to abnormalities in neuronal energy metabolism (Lin and Beal, 2006). In addition, AMPK is activated by various types of cellular stress that deplete ATP such as oxidative stress, which has been implicated in AD pathology (Lin and Beal, 2006; Ma and Klann, 2012). Indeed, it has been reported that AMPK activity, as evaluated by phosphorylation of Thr172, is robustly upregulated in postmortem AD brains (Vingtdeux et al., 2011). Furthermore, suppression of AMPK activity either pharmacologically or genetically has been shown to exert neuroprotective effects in cerebral ischemia (McCullough et al., 2005; Li et al., 2007; but see Kuramoto et al., 2007).

AMPK also regulates protein synthesis, which plays a critical role in consolidating long-lasting synaptic plasticity and longterm memory (Klann and Dever, 2004; Costa-Mattioli et al., 2009), and dysregulated protein synthesis recently was implicated in AD pathogenesis (Ma et al., 2013). Of note, it was shown that AMPK activity is important in maintaining protein synthesis-dependent forms of synaptic plasticity (Potter et al., 2010). Previous work, mainly in non-neuronal systems, has es- 
tablished that AMPK inhibits translation through at least two mechanisms: (1) phosphorylation of TSC2, which results in inhibition of the mammalian target of rapamycin complex 1 (mTORC1) pathway (Hoeffer and Klann, 2010) and (2) phosphorylation and activation of eukaryotic elongation factor 2 kinase (eEF2K), which subsequently phosphorylates and inhibits the activity of eEF2, thereby turning off the elongation step in translation (Horman et al., 2002; Hardie, 2004).

$\mathrm{AD}$ has been described as a disease of "synaptic failure" (Selkoe, 2002; Tanzi, 2005) and recently it was demonstrated that dendritic spine loss associated with amyloid $\beta$ (A $\beta$ ) synaptotoxicity is prevented by inhibiting AMPK signaling (Mairet-Coello et al., 2013). However, direct evidence linking AD-associated synaptic plasticity impairments and aberrant AMPK signaling has yet to be demonstrated. Herein, using pharmacological and genetic approaches, we directly tested the hypothesis that aberrant AMPK signaling underlies AD-associated synaptic dysfunction. Our findings reveal a previously unrecognized signaling module involved in $\mathrm{AD}$ pathogenesis and thus, novel therapeutic targets for this and other neurodegenerative diseases that result in dementia.

\section{Materials and Methods}

Mice. All mice (C57BL/6) were housed in the Transgenic Mouse Facility of New York University, compliant with the NIH Guide for Care and Use of Laboratory Animals. The facility is kept on a $12 \mathrm{~h}$ light/dark cycle, with a regular feeding and cage-cleaning schedule. Both male and female mice were used for all experiments. APP/PS1 $\left(\mathrm{APP}_{\text {swe }}+\mathrm{PSEN}_{\mathrm{dE} 9}\right)$ transgenic mice were purchased from the The Jackson Laboratory (Jankowsky et al., 2001). AMPK $\alpha 2$ knock-out (KO) mice were generated as described previously (Viollet et al., 2003b). All genotypes were determined by PCR.

Western blots of postmortem AD brain samples. For AMPK experiments (Fig. 1A), soluble protein extracts from brain sections were provided by the late Dr. Mark Smith from Case Western Reserve University. Samples were collected and prepared in accordance with the institution's Institutional Review Board-approved protocols as described previously (Bonda et al., 2010). Briefly, brain sections from $\mathrm{AD}(n=4$; age $72-89$ years $)$ and control ( $n=3$; age $65-86$ years) were homogenized in 10 volume of lysis buffer equipped with protease and phosphatase inhibitors (50 mM Tris$\mathrm{HCl}, \mathrm{pH} 7.6,0.02 \%$ sodium azide, $0.5 \%$ sodium deoxycholate, $0.1 \%$ SDS, $1 \%$ Nonidet P-40, $150 \mathrm{~mm} \mathrm{NaCl}, 1 \mathrm{~mm}$ phenylmethylsulfonyl fluoride, 1 $\mathrm{mg} / \mathrm{ml}$ aprotinin, $2 \mathrm{mg} / \mathrm{ml}$ antipain, and $1 \mathrm{~mm}$ sodium orthovanadate). Twenty micrograms of soluble protein extracts were prepared from brain samples and standard Western blotting techniques were used as described below. For eEF2 experiments (Fig. 5B), AD (Braak stages V-VI) and age-matched normal control cases were obtained from the Albert Einstein College of Medicine human brain bank (Bronx, NY). Brain samples were from the mid-temporal cortex. Samples were homogenized and sonicated in Tris-buffered saline containing 2\% SDS and $1 \times$ Complete protease inhibitor mixture (Roche Applied Science) and centrifuged at $100,000 \times g$ for $1 \mathrm{~h}$ at $4^{\circ} \mathrm{C}$. The resulting supernatants were analyzed by Western blotting for the indicated proteins.

Immunohistochemistry on postmortem $A D$ brain samples. Paraffinembedded hippocampal sections of postmortem human brain samples were obtained from one control and three AD patients, Braak stage 6 . Tissue was obtained from the Albert Einstein College of Medicine brain bank. Five micrometer thick sections of formalin-fixed, paraffinembedded brain tissue samples were immunostained with rabbit polyclonal antibodies directed against phospho-Thr-172 of AMPK (p-AMPK; Abcam; 1:200 dilution) as previously described (Vingtdeux et al., 2011). Briefly, the sections were deparaffinized by immersion in $x y-$ lene and hydration through graded ethanol solutions. Antigen recovery was performed by incubating the slides for $30 \mathrm{~min}$ at $70^{\circ} \mathrm{C}$ in $10 \mathrm{~mm}$ citrate buffer, $\mathrm{pH}$ 6.0. Endogenous peroxidase activity was inhibited by incubation in 3\% hydrogen peroxide and $0.25 \%$ Triton X-100 in Trisbuffered saline (TBS) for $30 \mathrm{~min}$ at room temperature (RT), after which slides were washed in TBS containing 0.05\% Triton X-100 (TBS-T) and blocked in 5\% normal goat serum, $1 \mathrm{mg} / \mathrm{ml} \mathrm{BSA}$, and $1 \mathrm{~mm} \mathrm{NaF}$ in TBS-T for $1 \mathrm{~h}$ at RT. Sections then were incubated in the presence of primary antibodies diluted in TBS-T containing $1 \%$ normal goat serum, $1 \mathrm{mg} / \mathrm{ml}$ $\mathrm{BSA}$, and $1 \mathrm{~mm} \mathrm{NaF}$ overnight at $4^{\circ} \mathrm{C}$ in a humidified chamber. After washing the sections were incubated with biotin-coupled, goat anti-rabbit secondary antibodies (1:1000 dilution; Southern Biotech) before incubation with streptavidin-horseradish peroxidase (1:1000 dilution; Southern Biotech) and visualization with diaminobenzidine tetrahydrochloride.

Western Blots and antibodies used for mouse experiments. Lysates were prepared as described previously (Banko et al., 2005). Equal amounts of protein from each sample were loaded on $4-12 \%$ Tris-glycine SDSPAGE (Invitrogen) gels. After transfer, membranes were blocked for at least $30 \mathrm{~min}$ at room temperature with blocking buffer [5\% nonfat dry milk in TBS containing $0.1 \%$ Tween 20 (TBS-T)], then probed overnight at $4^{\circ} \mathrm{C}$ using the following primary antibodies (at dilutions of 1:1000, unless otherwise specified): phospho-AMPK (Thr172) and AMPK (Cell Signaling Technology), phospho-LKB1 (Ser428) and LKB1 (Cell Signaling Technology), phospho-Akt (Ser473) and Akt (Cell Signaling Technology), phospho-eEF2 (Thr56) and eEF2 (Cell Signaling Technology), actin (Sigma; dilution 1:10,000), GAPDH (Cell Signaling Technology; dilution 1:10,000), phospho-mTOR (Ser2448) and mTOR (Cell Signaling Technology), and eEF1A (Millipore). Densitometric analysis was performed using Scion Image software.

Hippocampal slice preparation and electrophysiology. Acute $400 \mu \mathrm{m}$ transverse hippocampal slices were prepared using a vibratome as described previously (Ma et al., 2011). The slices were maintained at RT in artificial CSF (ACSF) for at least $2 \mathrm{~h}$ before removal for experiments. For electrophysiology experiments, monophasic, constant-current stimuli $(100 \mu \mathrm{s})$ were delivered with a bipolar silver electrode placed in the stratum radiatum of area CA3, and the fEPSPs were recorded in the stratum radiatum of area CA1. LTP was induced with a high-frequency stimulation (HFS) protocol consisting of two $1 \mathrm{~s}$ long $100 \mathrm{~Hz}$ trains, separated by $60 \mathrm{~s}$, delivered at $70-80 \%$ of the intensity that evoked spiked fEPSPs. LTD was induced with 300 pulses of low-frequency stimulation (LFS) at $1 \mathrm{~Hz}$.

Immunofluorescence and confocal microscopy. Slices were fixed overnight in ice-cold $4 \%$ paraformaldehyde in PBS. Free-floating sections were blocked with $10 \%$ normal goat serum, $1 \%$ BSA, and $0.1 \%$ Na azide in PBS for $2 \mathrm{~h}$, and incubated with primary antibody phospho-AMPK (Thr172; Santa Cruz Biotechnology. Alexa Fluor 568 secondary antibodies (Invitrogen) were used. The sections were imaged using a Leica TCS SP5 confocal microscope at $630 \times$. All parameters (pinhole, contrast, gain, and offset) were held constant for all sections from the same experiment.

SUnSET protein synthesis assay. Proteins were labeled using a protocol adapted from the SUnSET method (Schmidt et al., 2009). Hippocampal slices were incubated with puromycin $(1 \mu \mathrm{g} / \mathrm{ml})$ for $60 \mathrm{~min}$ throughout the drug-treatment experiments. At the end of drug treatment slices were harvested and frozen on dry ice. Area CA1 was microdissected and protein lysates were prepared for Western blotting. Puromycin-labeled proteins were identified using the mouse monoclonal antibody 12D10. Protein synthesis levels were determined by taking total lane density in the molecular weight range of $10-250 \mathrm{kDa}$.

Drug treatments. Drugs were prepared as stock solution in DMSO and diluted into ACSF to its final concentration during experiments. The final concentration of the drugs and the source were as follows: Compound C (CC; $5 \mu \mathrm{m}$; Calbiochem), NH125 (1 $\mu \mathrm{M}$; Calbiochem), A $\beta$ (1-42; $500 \mathrm{~nm}$; Tocris Bioscience). Incubation of hippocampal slices with drugs was performed in either recording chambers or maintenance chambers as needed.

Data analysis. Data are presented as mean + SEM. Summary data are presented as group means with SE bars. For comparison between two groups, a two-tailed independent Student's $t$ test was used. For comparisons between multiple groups, an ANOVA was used followed by individual post hoc tests when applicable. Error probabilities of $p<0.05$ were considered statistically significant.

\section{Results}

Increased AMPK phosphorylation in AD brains

We first examined whether AMPK activity is altered in AD by measuring phosphorylation at the Thr172 site on the $\alpha$-subunit of AMPK. First, Western blot experiments on hippocampal slices 
A A AD mouse model human AD brains synthetic $A \beta$

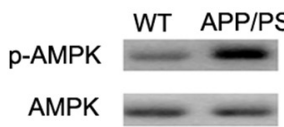

vehicle $A \beta$

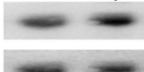

B

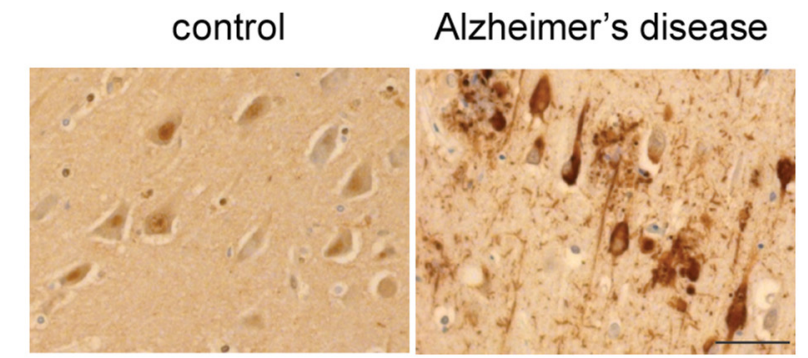

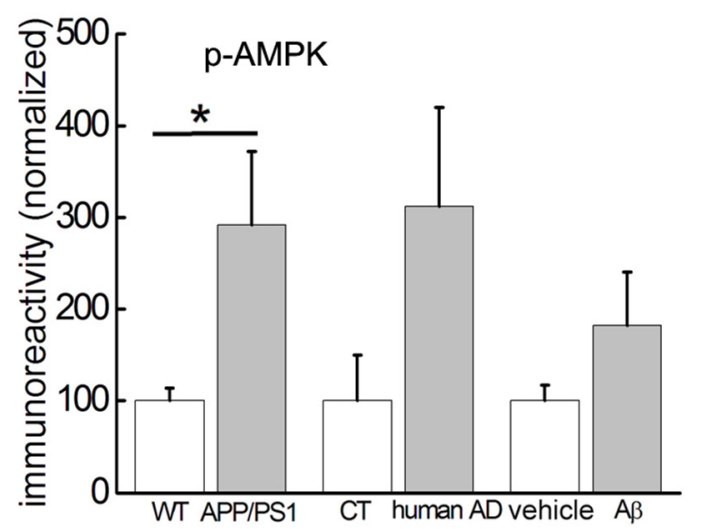

C

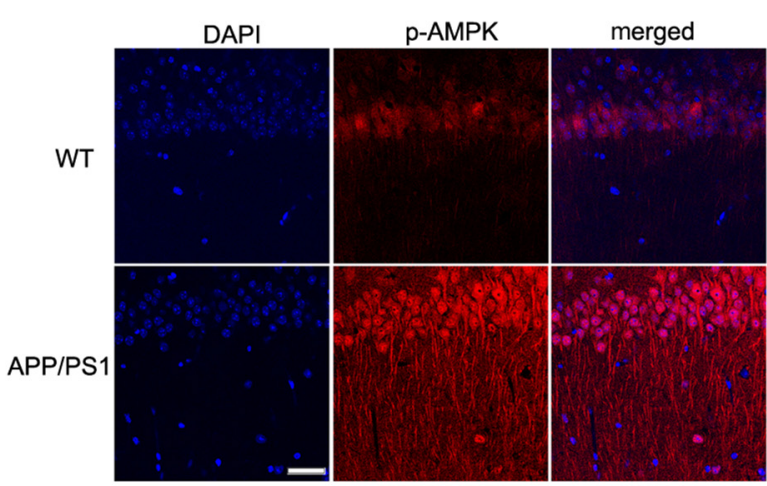

D

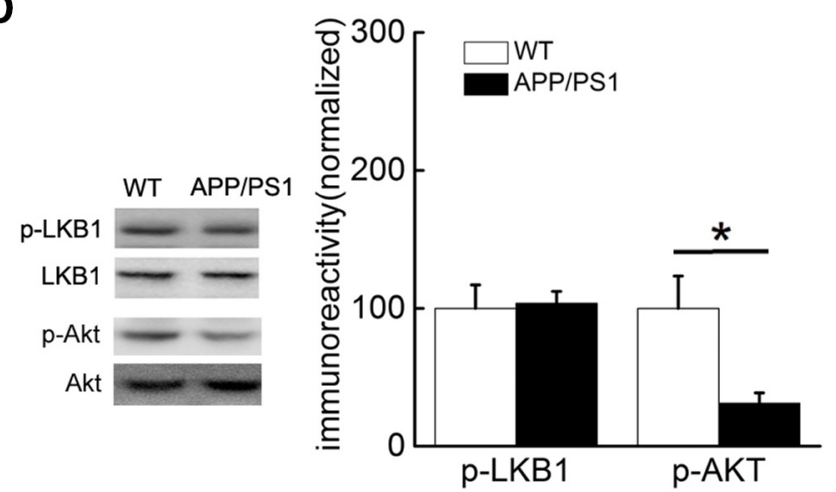

Figure 1. Increased AMPK phosphorylation in Alzheimer's disease. A, Western blot experiments showing AMPK phosphorylation (Thr172) in the hippocampus of APP/PS1 mice (left, $n=9$ for WT and $n=6$ for APP/PS1), postmortem human AD patients (middle, $n=4)$, and hippocampal slices treated with A $\beta(500 \mathrm{~nm}$; right, $n=6)$. Cumulative data are shown in the bar graph. Unpaired independent $t$ test; ${ }^{*} p<0.05$. B, DAB staining (toluidine blue counterstaining) revealed increased AMPK phosphorylation in area CA1 of hippocampus of human AD samples; $20 \times$. Scale bar, $50 \mu \mathrm{m}$. C, Immunofluorescence/confocal microscopy showing that phospho-AMPK (Thr172) was increased in area CA1 of hippocampal slices from APP/PS1 mice. Scale bar, $50 \mu \mathrm{m}$. D, Western blot experiments of hippocampal homogenates from APP/PS1 mice showing no change in LKB1 phosphorylation (Ser428; $n=5$ ), but decreased levels of Akt phosphorylation (Ser473; $n=3$ ). Cumulative data are shown in bar graph. Unpaired independent $t$ test; ${ }^{*} p<0.05$.

from 10- to 12-month-old $\mathrm{APP}_{\text {swe }} / \mathrm{PS} 1_{\mathrm{dE} 9}$ (APP/PS1) AD model mice (Jankowsky et al., 2001) revealed an elevated phosphorylation of AMPK compared with wild-type littermates (Fig. 1A, top left). Interestingly, this aberrant AMPK phosphorylation was not observed in either cerebellum or prefrontal cortex of APP/PS1 mice (data not shown). We further examined hippocampal tissue from postmortem human $\mathrm{AD}$ patients with Western blot and immunohistochemical analyses and found that AMPK phosphorylation was increased compared with age-matched controls (Fig. 1A, top middle, $B$ ). Increased AMPK phosphorylation in the hippocampus of $\mathrm{AD}$ brains was manifested in degenerating neurons and dystrophic neurites (Fig. $1 B$ ), two hallmarks of AD neuropathology. We also treated wild-type mouse hippocampal slices with exogenous $\mathrm{A} \beta 1-42(500 \mathrm{~nm})$ and observed a trend toward increased levels of phosphorylated AMPK (Fig. 1A, top right). To gain insight into the cellular distribution of AMPK regulation in $\mathrm{AD}$ model mice, we performed immunofluorescence combined with confocal microscopy on hippocampal slices. As revealed in Figure $1 C$, immunostaining for phosphorylated AMPK was markedly higher in both the soma and dendrites of stratum radiatum in hippocampal area CA1 of APP/PS1 mice compared with wild-type littermates. These findings indicate that
AMPK phosphorylation is elevated in the hippocampus of $\mathrm{AD}$ model mice and $\mathrm{AD}$ patients.

We further investigated the signaling pathways involved in the AMPK dysregulation in AD model mice. Notably, we did not detect a change in the phosphorylation levels of LKB1 (Fig. 1D), which has been established as an upstream kinase for AMPK in non-neuronal systems (Hardie, 2004). In contrast and consistent with previous reports (Kovacic et al., 2003; Jo et al., 2011; Ma et al., 2012), we observed decreased phosphorylation of Akt (Ser473) in the hippocampus of APP/PS1 mice (Fig. 1D), consistent with previous findings that Akt negatively regulates AMPK resulting in decreased phosphorylation at Thr172 (Kovacic et al., 2003; Hahn-Windgassen et al., 2005).These findings suggest that AMPK activity is abnormally upregulated in AD brains.

\section{Alterations in hippocampal synaptic plasticity induced by $\mathrm{A} \beta$} are rescued by the AMPK inhibitor CC

LTP is a form of synaptic plasticity that is widely believed to be a cellular substrate for memory formation (Malenka, 2003). If AMPK upregulation (hyperphosphorylation) plays a role in $\mathrm{AD}$ pathogenesis, one would predict that blunting of AMPK activity would alleviate $\mathrm{AD}$-associated impairments in synaptic plasticity 
A

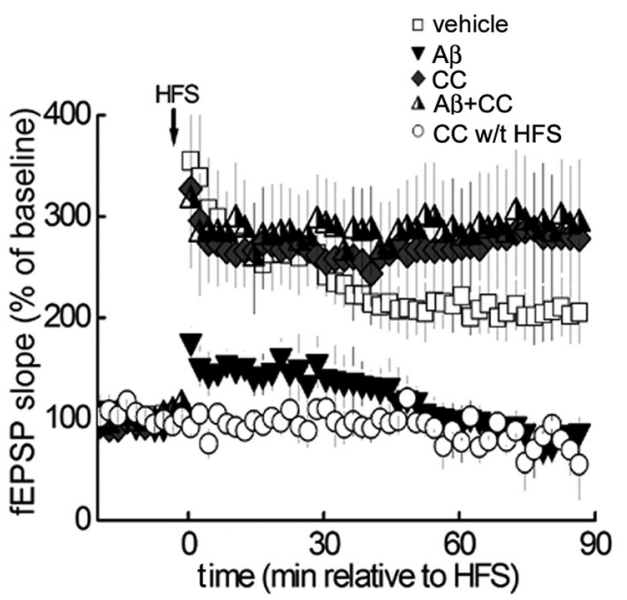

C

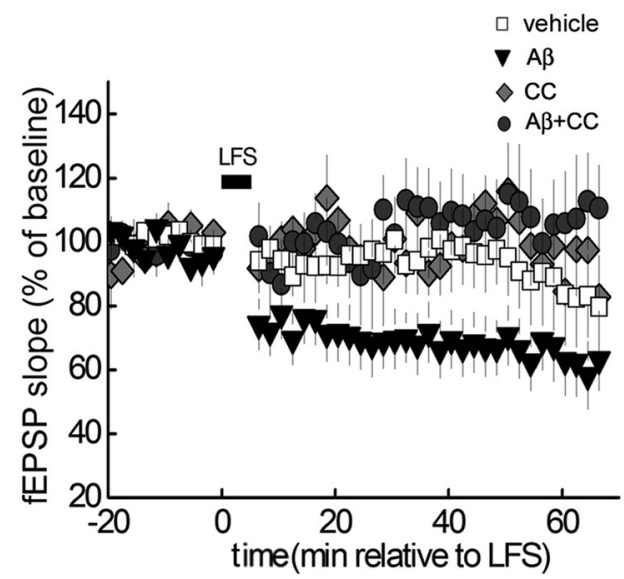

B

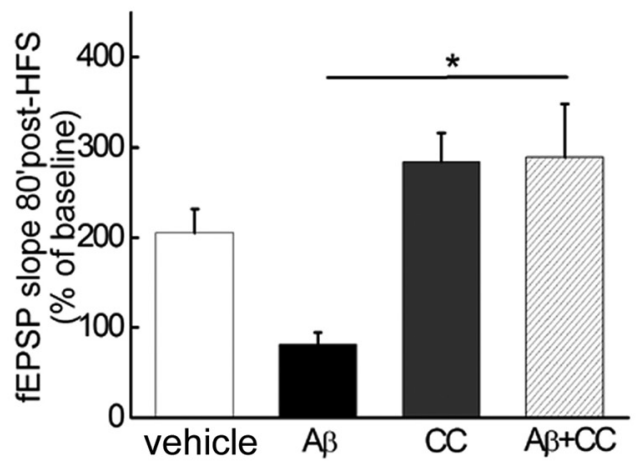

D

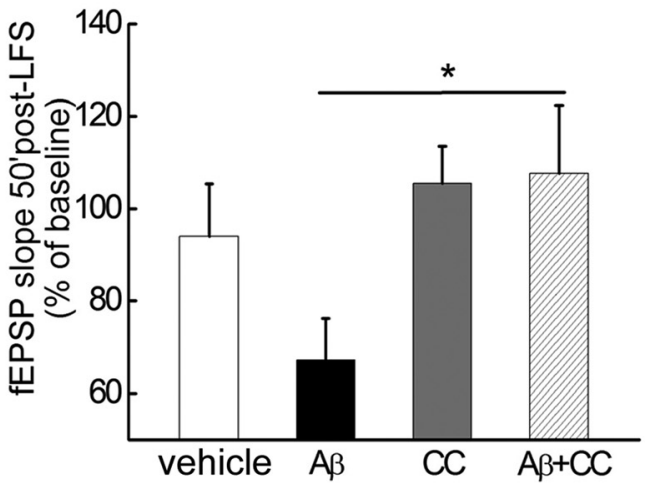

Figure 2. Hippocampal synaptic plasticity impairments caused by A $\beta$ are rescued by AMPK inhibitor $C C . A$, HFS-induced LTP in vehicle-treated hippocampal slices (open squares), but not in slices treated with exogenous $\mathrm{A} \beta$ (dark gray triangles). In contrast, $C(\mathrm{C}(5 \mathrm{M})$ enabled normal LTP induction in the presence of A $\beta$ (half-filled triangles). CC alone did not affect either HFS-induced LTP (dark gray diamonds) or baseline fEPSPs (open circles); $n=5$. B, Cumulative data showing mean fEPSP slopes 80 min after HFS based on LTP experiments in $A$. Unpaired independent $t$ test; ${ }^{*} p<0.05$. C, $A \beta(500 \mathrm{~nm}$ )-facilitated LTD (dark gray triangles, $n=11$ ) induced by a weak HFS ( $1 \mathrm{~Hz}, 300$ pulses), which normally did not induce LTD (open squares, $n=7$ ). In contrast, A $\beta$ did not induce LTD in the presence of $C C$ ( $5 \mu \mathrm{m}$; (ark gray circles, $n=6)$. D. Cumulative data showing mean fEPSP slopes 50 min after LFS based on LTD experiments in $C$. Unpaired independent $t$ test; ${ }^{*} p<0.05$.

that are a characteristic of AD pathophysiology (Rowan et al., 2005; Ma and Klann, 2012). To test this notion, the AMPK antagonist CC (5 $\mu$ m; Potter et al., 2010) was applied to hippocampal slices in the presence of $\mathrm{A} \beta 1-42$ (500 nM), which contains ample $A \beta$ oligomers in the preparation method that was used (Ma et al., 2010). Application of A $\beta$ itself to slices blocked LTP induced by HFS (Fig. $2 A, B$ ). Although CC alone did not affect LTP, it prevented $A \beta$-induced LTP failure (Fig. $2 A, B$ ). Thus, inhibiting AMPK prevents $\mathrm{A} \beta$-induced impairments in hippocampal LTP.

$\mathrm{A} \beta$ also is known to facilitate LTD, another form of hippocampal synaptic plasticity (Li et al., 2009; Ma et al., 2012). We first confirmed that in our conditions A $\beta$ facilitated LTD induction using a weak LFS protocol (see Materials and Methods), which by itself did not elicit LTD (Fig. 2C,D). In comparison, in slices treated with the AMPK inhibitor CC, the LTD enhancement induced by A $\beta$ was absent (Fig. $2 C, D$ ). These results, coupled with the results from the LTP experiments (Fig. 2A,B), indicate that $A \beta$-induced alterations in hippocampal synaptic plasticity are prevented by inhibition of AMPK.
Impaired LTP in APP/PS1 AD model mice is alleviated by the AMPK inhibitor CC

To further explore the role of AMPK hyperactivity in AD-related impairments in hippocampal synaptic plasticity, we used slices from APP/PS1 transgenic mice that model AD (Jankowsky et al., 2001). Consistent with previous reports (Ma et al., 2011), hippocampal LTP in APP/PS1 mice (10 to 12 months old) was inhibited (Fig. $3 A, B$ ). However, when slices from APP/PS1 mice were treated with CC, LTP was significantly enhanced (Fig. $3 A, B)$. Moreover, LTP was not altered in CC-treated slices from wild-type mice (Fig. $3 C$ ). Defects in de novo protein synthesis have been linked to synaptic dysfunction in APP/PS1 mice (Ma et al., 2013). To examine the effects of AMPK inhibition on de novo protein synthesis in APP/PS1 mice, we performed SUnSET experiments on hippocampal slices and observed that the levels of newly synthesized proteins in area CA1 were increased by CC, compared with the vehicle control groups (Fig. $3 D, E$ ). In addition, we also observed increased de novo protein synthesis in wildtype hippocampal slices treated with CC (Fig. 3D,E). These results are consistent with the idea that hyperactive AMPK con- 
A

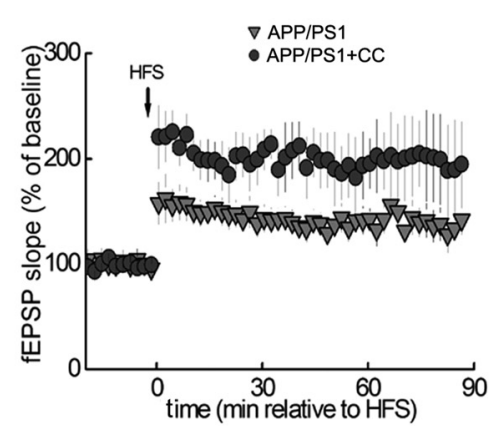

D

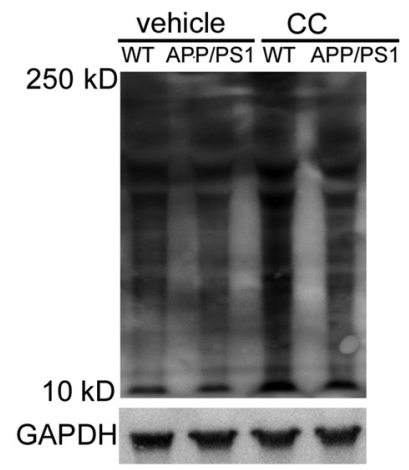

B

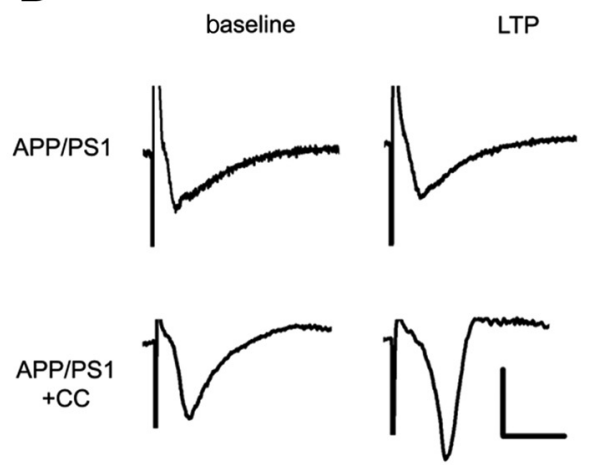

E
C

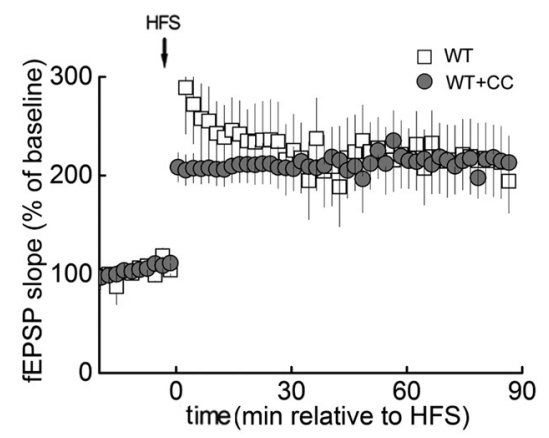

Figure 3. LTP impairments in APP/PS1 AD model mice are alleviated by the AMPK inhibitor CC. $A$, HFS-induced LTP was impaired in slices from APP/PS1 mice (gray triangles, $n=7$ ) and was improved by CC treatment (dark gray circles, $n=6$ ). $\boldsymbol{B}$, Representative fEPSP traces before and after HFS for LTP experiments shown in $\boldsymbol{A}$. $\boldsymbol{C}$, HFS-induced LTP was not altered in CC-treated slices derived from wild-type (WT) mice (gray circles, $n=8$ ). $D$, Representative blot showing (C treatment increased de novo protein synthesis (assayed by SUnSET) in area CA1 of hippocampus of WT and APP/PS1mice. $\boldsymbol{E}$, Cumulative data showing CC treatment experiments; $n=6$. One-way ANOVA followed by post hoc Tukey test; ${ }^{*} p<0.05$.

tributes to decreased de novo protein synthesis, which is associated with synaptic dysfunction in $\mathrm{AD}$.

\section{A $\beta$-induced LTP failure is prevented by genetic removal of the $\alpha 2$-subunit of AMPK}

Previous studies have revealed that both $\alpha 1$ and $\alpha 2$ isoforms of AMPK are expressed in mouse brains, but that $\alpha 2$ is the predominant catalytic subunit in neurons of the cortex and hippocampus (Turnley et al., 1999). It is also noteworthy that AMPK $\alpha 2$ knockout $(\mathrm{KO})$ mice are protected from stroke damage, whereas AMPK $\alpha 1 \mathrm{KO}$ mice are not (Li et al., 2007). Therefore, we examined $\mathrm{A} \beta$-induced impairments in LTP in mice that lack the $\alpha 2$ subunit of AMPK (Viollet et al., 2003a,b). In hippocampal slices derived from AMPK $\alpha 2 \mathrm{KO}$ mice, LTP was comparable to that in wild-type mice starting $30 \mathrm{~min}$ post-HFS (Fig. $4 A$ ). In contrast, the $\mathrm{A} \beta$-induced LTP impairment observed in slices of wild-type mice was prevented in slices from AMPK $\alpha 2 \mathrm{KO}$ mice (Fig. $4 B-$ $D)$. These findings are consistent with the LTP studies using the AMPK inhibitor (Figs. 2, 3) and provide further evidence of a causal relationship between aberrant AMPK signaling and impairments in synaptic plasticity associated with $\mathrm{AD}$.

\section{Inhibition of eEF2K activity rescues $\mathrm{A} \boldsymbol{\beta}$-induced impairment in LTP}

De novo protein synthesis is critical for the consolidation of longterm synaptic plasticity and memory (Klann and Dever, 2004; Alberini, 2008). Of note, previous studies from non-neuronal systems have indicated that AMPK activation inhibits protein synthesis through either TSC2-mTORC1 or eEF2K-eEF2 signal- ing pathways (Horman et al., 2002; Inoki et al., 2006). Thus, we hypothesized that the effects of aberrant AMPK activity on ADrelated synaptic dysfunction would be mediated via the aforementioned signaling pathways that control translation. In correlation with AMPK activation (Fig. $1 A, B$ ), we observed a marked increase in eEF2 phosphorylation (Thr56) in the hippocampus of APP/PS1 mice (Fig. 5A). Notably, Western blots performed on brain tissues from postmortem human $\mathrm{AD}$ patients also revealed a significant increase in eEF2 phosphorylation compared with age-matched controls (Fig. 5B). Moreover, levels of phosphorylated eEF2 were reduced in the hippocampus of AMPK $\alpha 2 \mathrm{KO}$ mice (Fig. $5 C$ ). These findings are consistent with previous results from cell culture studies indicating that activation of AMPK results in eEF2 phosphorylation via eEF2K and inhibition of protein synthesis (Horman et al., 2002; Browne et al., 2004; Leprivier et al., 2013). We did not observe changes in the phosphorylation of TSC2 (Ser1387) in hippocampal tissue from APP/PS1 mice (Fig. 5D) and removal of the $\alpha 2$-subunit of AMPK did not affect mTORC1 signaling as indicated by unaltered levels of phosphorylated mTOR (Ser2448) and the expression of elongation factor 1A (eEF1A; Tsokas et al., 2005; Fig. 5E). These results suggest that the activation of AMPK alters eEF2K-eEF2 signaling rather than TSC2-mTORC1 signaling in APP/PS1 mice.

We proceeded to ask whether decreasing eEF2 phosphorylation could improve A $\beta$-induced LTP deficits by using NH125, a small molecule compound that is a selective and efficacious inhibitor of eEF2K (Arora et al., 2003). Notably, in hippocampal slices treated with $\mathrm{NH} 125$ in the presence of $\mathrm{A} \beta$, HFS-induced LTP was maintained. In contrast, NH125 alone did not impact 
A

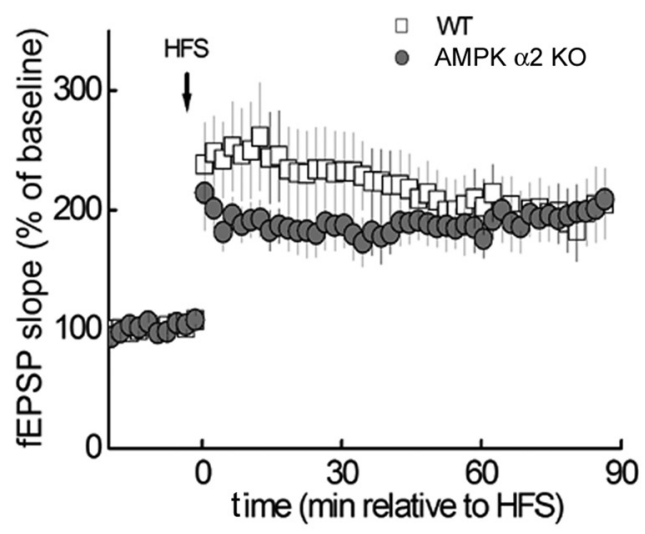

C

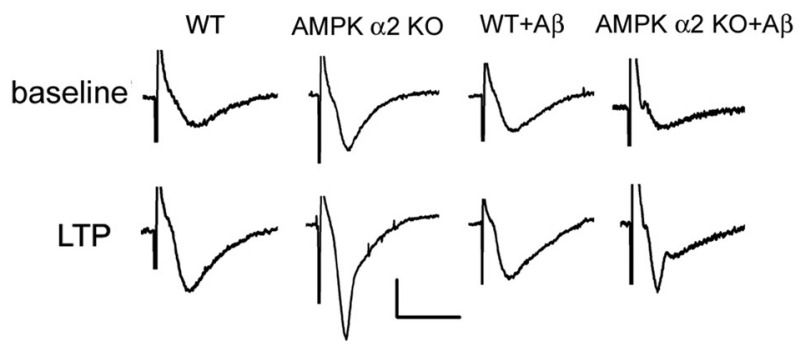

D
B

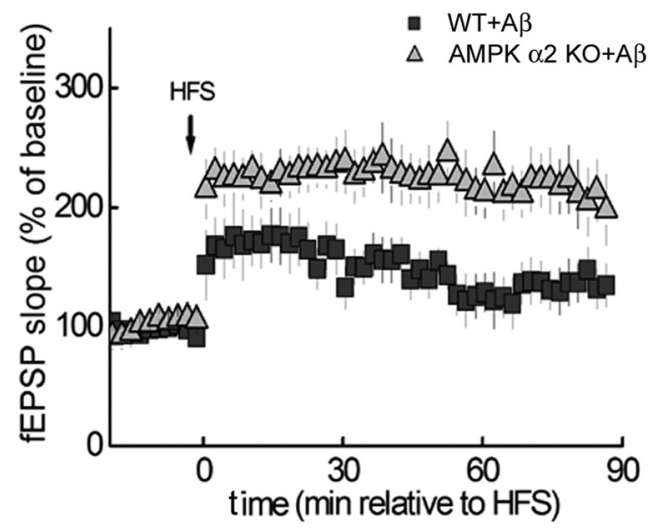

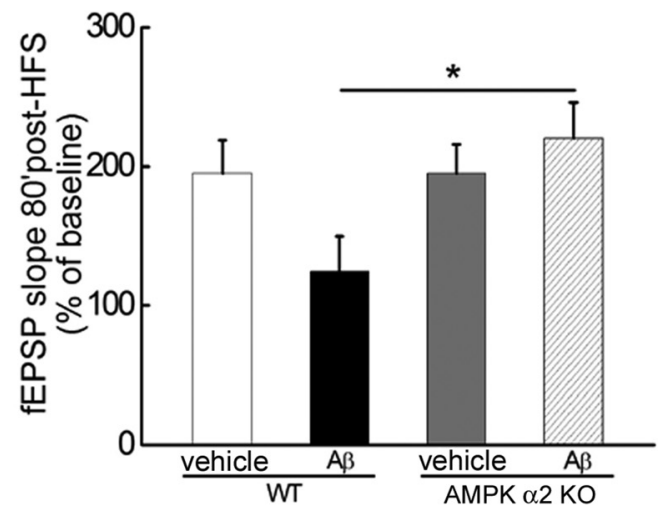

Figure 4. A $\beta$-induced LTP failure is prevented by genetic removal of the $\alpha 2$-subunit of AMPK. $A$, Comparable LTP was induced by HFS in hippocampal slices from either wild-type (WT; open squares, $n=7$ ) or AMPK $\alpha 2$ KO mice (gray circles, $n=7$ ). $B$, HFS-induced LTP was inhibited by exogenous A $\beta$ (dark gray squares, $n=5$ ), but maintained in slices derived from AMPK $\alpha 2$ KO mice in the presence of $A \beta$ (gray triangles, $n=5$ ). C, Representative fEPSP traces before and after HFS for LTP experiments shown in $A$ and $\boldsymbol{B}$. D. Cumulative data showing mean fEPSP slopes 80 min after HFS based on LTP experiments in $\boldsymbol{A}$ and $\boldsymbol{B}$. Unpaired independent $t$ test; ${ }^{*} p<0.05$.

LTP (Fig. 5F-H). Collectively, these findings suggest that hyperphosphorylation of eEF2 via eEF2K activation plays a critical role in mediating the effects of AMPK hyperactivation on AD-related synaptic dysfunction.

\section{Discussion}

Present disease-modifying strategies for AD in clinical trials, such as $\mathrm{A} \beta$ antibody immunotherapy and gamma secretase inhibitors, have met with limited success (Mangialasche et al., 2010). A better understanding of the molecular and cellular mechanisms underlying $\mathrm{AD}$-associated synaptic dysfunction has the potential to provide additional targets for novel therapeutics for this devastating neurodegenerative disease. Numerous studies have demonstrated that overproduction of reactive oxygen species (ROS) and oxidative stress, presumably causing energy imbalance, play an important role in $\mathrm{AD}$-associated impairments of synaptic function and memory formation (Lin and Beal, 2006; Massaad and Klann, 2011; Ma and Klann, 2012). However, recent results from human trials suggest it is difficult to remove ROS from multiple sources with general antioxidants (Galasko et al., 2012). In the current study, we directly examined the impact of inhibiting AMPK, an energy sensor activated by ROS/oxidative stress, on $\mathrm{AD}$-associated synaptic dysfunction. We found that either pharmacological or genetic inhibition of AMPK can prevent disruptions in synaptic plasticity caused by either exogenous $A \beta$ exposure or displayed in APP/PS1 transgenic mice, consistent with the observation that AMPK signaling is hyperactive in $\mathrm{AD}$ brains. Furthermore, our studies revealed that eEF2K and its substrate eEF2 are key downstream effectors that may mediate the effects of hyperactive AMPK in AD pathophysiology, suggesting that $\mathrm{eEF} 2 \mathrm{~K}$ is involved in $\mathrm{AD}$ pathogenesis and could be a potential novel therapeutic target.

Whether inhibition of AMPK activity would be either beneficial or detrimental in AD is a subject under debate (Salminen et al., 2011). On the one hand, activation of AMPK in response to cellular stress is considered protective and has been established as important in enhancing lifespan based on studies primarily from non-mammalian systems (Apfeld et al., 2004; Mair et al., 2011); the anti-aging effects of AMPK activation have been proposed to protect against neurodegenerative diseases, including AD (Douglas and Dillin, 2010). On the other hand, multiple lines of evidence indicate that activation of AMPK could result in detrimental outcomes and that restraining AMPK activity confers neuroprotective effects in certain types of brain injury such as stroke (McCullough et al., 2005; Li et al., 2007; Li and McCullough, 2010). In light of the current findings in which we demonstrated that blocking AMPK activity alleviates ADassociated synaptic plasticity alterations, along with a recent study showing that downregulation of AMPK signaling protects 
A

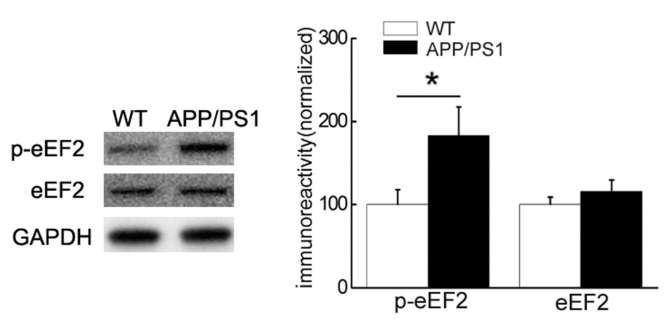

C

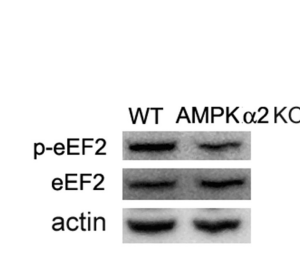

F

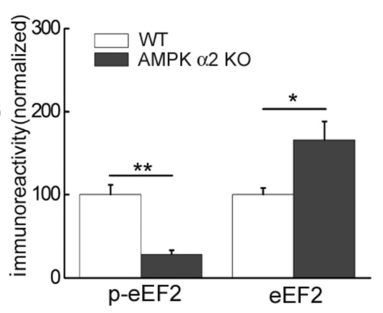

B

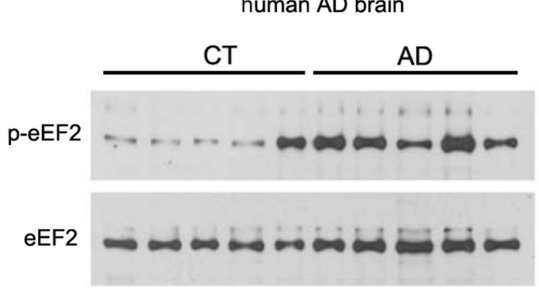

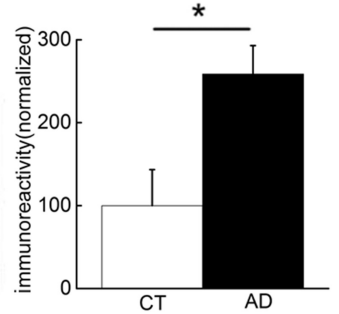

D

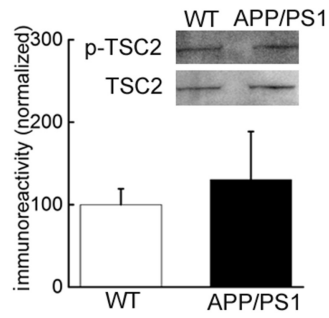

E

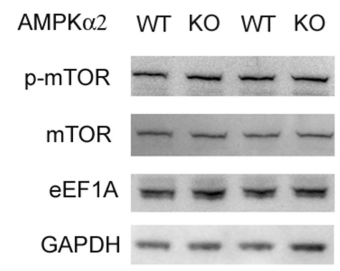

H
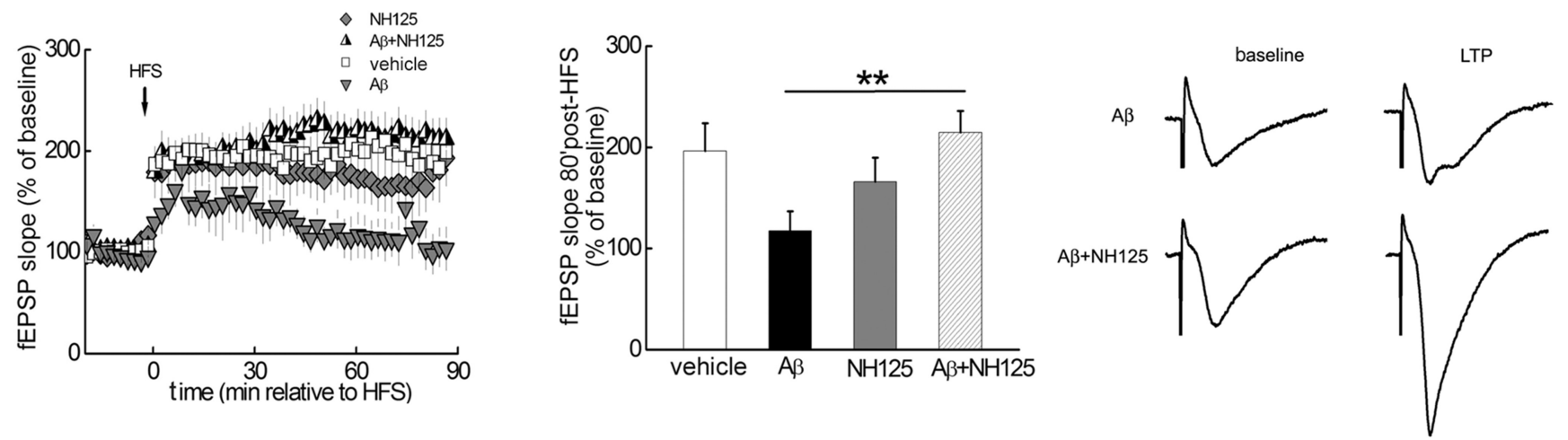

Figure 5. Inhibition of eEF2K activity rescues A $\beta$-induced impairments in LTP. A, Western blot demonstrating that levels of phosphorylated eEF2 (Thr56), but not total eEF2, were increased in the hippocampus of APP/PS1 mice. Cumulative data are shown in the bar graph; $n=8$ for wild-type (WT), $n=7$ for APP/PS1. Unpaired independent $t$ test; ${ }^{*} p<0.05$. B, Western blot demonstrating that eEF2 phosphorylation at Thr56 was increased in postmortem human AD brain tissues compared with age-matched controls. Cumulative data are shown in the bar graph; $n=$ 5 for both groups. Unpaired independent $t$ test; ${ }^{*} p<0.05$. C, Western blot experiments showing that levels of eEF2 phosphorylation were decreased in AMPK $\alpha 2$ KO mice. Cumulative data are shown in the bar graph; $n=6$. Unpaired independent $t$ test; ${ }^{*} p<0.05$.D. Western blot experiments showing that levels of TSC2 phosphorylation (Ser1387) were not altered in hippocampus of APP/PS1 mice; $n=6$. Unpaired independent $t$ test; $p>0.05$. E, Phosphorylation of mTOR (Ser2448) and expression of eEF1A were not affected in the hippocampus of AMPK $\alpha 2$ KO mice. Blots shown are representative of three independent experiments. $\boldsymbol{F}, A \beta$ caused LTP failure (gray triangles, $n=9$ ) compared with normal LTP induction in slices treated with vehicle (open squares, $n=9$ ). Treatment of hippocampal slices with the eEF2K inhibitor NH125 rescued A $\beta$-induced LTP impairment (half-filled triangles, $n=7$ ), whereas NH125 alone did not alter LTP (gray diamonds, $n=6$ ). $\boldsymbol{G}$, Cumulative data showing mean fEPSP slopes 80 min after HFS based on LTP experiments in $\boldsymbol{F}$. Unpaired independent $t$ test; ${ }^{*} p<0.05$. $\boldsymbol{H}$, Representative fEPSP traces before and after HFS for LTP experiments with $\mathrm{A} \beta$ treatment in the presence of either $\mathrm{NH} 125$ or vehicle shown in $\boldsymbol{F}$.

against $\mathrm{A} \beta$-induced loss of synapses (Mairet-Coello et al., 2013), we propose that the neuronal effects of AMPK activation during stress are conditional and contingent on the phase and/or potency of the specific cellular stress factors. In other words, activation of AMPK in response to a modest and transient type of assault would likely be protective in restoring the homeostasis of energy metabolism. However, during prolonged and/or severe cellular stress that would occur in either late-stage aging or in pathological conditions including ischemia or $\mathrm{AD}$, the ability of AMPK to balance energy homeostasis would be overwhelmed and its detrimental effects would in turn be amplified, further facilitating the damage caused by cellular stress. It should also be noted that as a crucial signaling node, AMPK is connected to many downstream effectors.
Consistent with the idea that prolonged activation of AMPK results in detrimental effects in $\mathrm{AD}$ are the results of the eEF2 experiments in the current study. AMPK activation leads to the activation of eEF2K, which in turn phosphorylates and inhibits the activity of eEF2, a translation factor that regulates the elongation step of mRNA translation. Although a transient, initial shutdown of protein synthesis would normally benefit cells by saving energy (from the energy-consuming process of new protein synthesis) to cope with the stress insult, prolonged and irreversible impairments in translational capacity would unavoidably hamper long-lasting synaptic plasticity and memory formation because de novo protein synthesis is essential for both processes (Richter and Klann, 2009). 
In summary, the central status of AMPK as an energy metabolism master regulator makes it an attractive candidate for $\mathrm{AD}$ therapy. However, for the same reason one should be extremely cautious about either activating or inhibiting AMPK in patients until a better understanding of the profound effects it may have on molecular signaling and cellular functions involved in cognition are more fully delineated.

\section{References}

Alberini CM (2008) The role of protein synthesis during the labile phases of memory: revisiting the skepticism. Neurobiol Learn Mem 89:234-246. CrossRef Medline

Apfeld J, O'Connor G, McDonagh T, DiStefano PS, Curtis R (2004) The AMP-activated protein kinase AAK-2 links energy levels and insulin-like signals to lifespan in C. elegans. Genes Dev 18:3004-3009. CrossRef Medline

Arora S, Yang JM, Kinzy TG, Utsumi R, Okamoto T, Kitayama T, Ortiz PA, Hait WN (2003) Identification and characterization of an inhibitor of eukaryotic elongation factor 2 kinase against human cancer cell lines. Cancer Res 63:6894-6899. Medline

Banko JL, Poulin F, Hou L, DeMaria CT, Sonenberg N, Klann E (2005) The translation repressor 4E-BP2 is critical for eIF4F complex formation, synaptic plasticity, and memory in the hippocampus. J Neurosci 25:95819590. CrossRef Medline

Bonda DJ, Mailankot M, Stone JG, Garrett MR, Staniszewska M, Castellani RJ, Siedlak SL, Zhu X, Lee HG, Perry G, Nagaraj RH, Smith MA (2010) Indoleamine 2,3-dioxygenase and 3-hydroxykynurenine modifications are found in the neuropathology of Alzheimer's disease. Redox Rep 15: 161-168. CrossRef Medline

Browne GJ, Finn SG, Proud CG (2004) Stimulation of the AMP-activated protein kinase leads to activation of eukaryotic elongation factor 2 kinase and to its phosphorylation at a novel site, serine 398. J Biol Chem 279: 12220-12231. CrossRef Medline

Costa-Mattioli M, Sossin WS, Klann E, Sonenberg N (2009) Translational control of long-lasting synaptic plasticity and memory. Neuron 61:10-26. CrossRef Medline

Douglas PM, Dillin A (2010) Protein homeostasis and aging in neurodegeneration. J Cell Biol 190:719-729. CrossRef Medline

Galasko DR, Peskind E, Clark CM, Quinn JF, Ringman JM, Jicha GA, Cotman C, Cottrell B, Montine TJ, Thomas RG, Aisen P (2012) Antioxidants for Alzheimer disease: a randomized clinical trial with cerebrospinal fluid biomarker measures. Arch Neurol 69:836-841. Medline

Hahn-Windgassen A, Nogueira V, Chen CC, Skeen JE, Sonenberg N, Hay N (2005) Akt activates the mammalian target of rapamycin by regulating cellular ATP level and AMPK activity. J Biol Chem 280:32081-32089. CrossRef Medline

Hardie DG (2004) The AMP-activated protein kinase pathway-new players upstream and downstream. J Cell Sci 117:5479-5487. CrossRef Medline

Hardie DG, Ross FA, Hawley SA (2012) AMPK: a nutrient and energy sensor that maintains energy homeostasis. Nat Rev Mol Cell Biol 13:251-262. CrossRef Medline

Hoeffer CA, Klann E (2010) mTOR signaling: at the crossroads of plasticity, memory and disease. Trends Neurosci 33:67-75. CrossRef Medline

Holtzman DM, Morris JC, Goate AM (2011) Alzheimer's disease: the challenge of the second century. Sci Transl Med 3:77sr71 CrossRef Medline

Horman S, Browne G, Krause U, Patel J, Vertommen D, Bertrand L, Lavoinne A, Hue L, Proud C, Rider M (2002) Activation of AMP-activated protein kinase leads to the phosphorylation of elongation factor 2 and an inhibition of protein synthesis. Curr Biol 12:1419-1423. CrossRef Medline

Inoki K, Ouyang $\mathrm{H}$, Zhu T, Lindvall C, Wang Y, Zhang X, Yang Q, Bennett C, Harada Y, Stankunas K, Wang CY, He X, MacDougald OA, You M, Williams BO, Guan KL (2006) TSC2 integrates Wnt and energy signals via a coordinated phosphorylation by AMPK and GSK3 to regulate cell growth. Cell 126:955-968. CrossRef Medline

Jankowsky JL, Slunt HH, Ratovitski T, Jenkins NA, Copeland NG, Borchelt DR (2001) Co-expression of multiple transgenes in mouse CNS: a comparison of strategies. Biomol Eng 17:157-165. Medline

Jo J, Whitcomb DJ, Olsen KM, Kerrigan TL, Lo SC, Bru-Mercier G, Dickinson B, Scullion S, Sheng M, Collingridge G, Cho K (2011) A $\beta(1-42)$ inhibition of LTP is mediated by a signaling pathway involving caspase-3, Akt1 and GSK-3 $\beta$. Nat Neurosci 14:545-547. CrossRef Medline
Klann E, Dever TE (2004) Biochemical mechanisms for translational regulation in synaptic plasticity. Nat Rev Neurosci 5:931-942. CrossRef Medline

Kovacic S, Soltys CL, Barr AJ, Shiojima I, Walsh K, Dyck JR (2003) Akt activity negatively regulates phosphorylation of AMP-activated protein kinase in the heart. J Biol Chem 278:39422-39427. CrossRef Medline

Kuramoto N, Wilkins ME, Fairfax BP, Revilla-Sanchez R, Terunuma M, Tamaki K, Iemata M, Warren N, Couve A, Calver A, Horvath Z, Freeman K, Carling D, Huang L, Gonzales C, Cooper E, Smart TG, Pangalos MN, Moss SJ (2007) Phospho-dependent functional modulation of GABA(B) receptors by the metabolic sensor AMP-dependent protein kinase. Neuron 53:233-247. CrossRef Medline

Leprivier G, Remke M, Rotblat B, Dubuc A, Mateo A-RF, Kool M, Agnihotri S, El-Naggar A, Yu B, Somasekharan SP, Faubert B, Bridon G, Tognon CE, Mathers J, Thomas R, Li A, Barokas A, Kwok B, Bowden M, Smith S, et al. (2013) The eEF2 kinase confers resistance to nutrient deprivation by blocking translation elongation 153:1064-1079. CrossRef

Li J, McCullough LD (2010) Effects of AMP-activated protein kinase in cerebral ischemia. J Cereb Blood Flow Metab 30:480-492. CrossRef Medline

Li J, Zeng Z, Viollet B, Ronnett GV, McCullough LD (2007) Neuroprotective effects of adenosine monophosphate-activated protein kinase inhibition and gene deletion in stroke. Stroke 38:2992-2999. CrossRef Medline

Li S, Hong S, Shepardson NE, Walsh DM, Shankar GM, Selkoe D (2009) Soluble oligomers of amyloid Beta protein facilitate hippocampal longterm depression by disrupting neuronal glutamate uptake. Neuron 62 : 788-801. CrossRef Medline

Lin MT, Beal MF (2006) Mitochondrial dysfunction and oxidative stress in neurodegenerative diseases. Nature 443:787-795. CrossRef Medline

Ma T, Klann E (2012) Amyloid $\beta$ : linking synaptic plasticity failure to memory disruption in Alzheimer's Disease. J Neurochem 120 [Suppl 1]:140 148. CrossRef Medline

Ma T, Hoeffer CA, Capetillo-Zarate E, Yu F, Wong H, Lin MT, Tampellini D, Klann E, Blitzer RD, Gouras GK (2010) Dysregulation of the mTOR pathway mediates impairment of synaptic plasticity in a mouse model of Alzheimer's disease. PLoS One 5:e12845. CrossRef Medline

Ma T, Hoeffer CA, Wong H, Massaad CA, Zhou P, Iadecola C, Murphy MP, Pautler RG, Klann E (2011) Amyloid $\beta$-induced impairments in hippocampal synaptic plasticity are rescued by decreasing mitochondrial superoxide. J Neurosci 31:5589-5595. CrossRef Medline

Ma T, Du X, Pick JE, Sui G, Brownlee M, Klann E (2012) Glucagon-like peptide- 1 cleavage product GLP-1 (9-36) amide rescues synaptic plasticity and memory deficits in Alzheimer's Disease Model Mice. J Neurosci 32:13701-13708. CrossRef Medline

Ma T, Trinh MA, Wexler AJ, Bourbon C, Gatti E, Pierre P, Cavener DR, Klann E (2013) Suppression of eIF $2 \alpha$ kinases alleviates Alzheimer's diseaserelated plasticity and memory deficits. Nat Neurosci 16:1299-1305. CrossRef Medline

Mair W, Morantte I, Rodrigues AP, Manning G, Montminy M, Shaw RJ, Dillin A (2011) Lifespan extension induced by AMPK and calcineurin is mediated by CRTC-1 and CREB. Nature 470:404-408. CrossRef Medline

Mairet-Coello G, Courchet J, Pieraut S, Courchet V, Maximov A, Polleux F (2013) The CAMKK2-AMPK kinase pathway mediates the synaptotoxic effects of $A \beta$ oligomers through Tau phosphorylation. Neuron 78:94108. CrossRef Medline

Malenka RC (2003) The long-term potential of LTP. Nat Rev Neurosci 4:923-926. CrossRef Medline

Mangialasche F, Solomon A, Winblad B, Mecocci P, Kivipelto M (2010) Alzheimer's disease: clinical trials and drug development. Lancet Neurol 9:702-716. CrossRef Medline

Massaad CA, Klann E (2011) Reactive oxygen species in the regulation of synaptic plasticity and memory. Antioxid Redox Signal 14:2013-2054. CrossRef Medline

McCullough LD, Zeng Z, Li H, Landree LE, McFadden J, Ronnett GV (2005) Pharmacological inhibition of AMP-activated protein kinase provides neuroprotection in stroke. J Biol Chem 280:20493-20502. CrossRef Medline

Potter WB, O'Riordan KJ, Barnett D, Osting SM, Wagoner M, Burger C, Roopra A (2010) Metabolic regulation of neuronal plasticity by the energy sensor AMPK. PLoS One 5:e8996. CrossRef Medline

Querfurth HW, LaFerla FM (2010) Alzheimer's disease. N Engl J Med 362: 329-344. CrossRef Medline 
Richter JD, Klann E (2009) Making synaptic plasticity and memory last: mechanisms of translational regulation. Genes Dev 23:1-11. CrossRef Medline

Rowan MJ, Klyubin I, Wang Q, Anwyl R (2005) Synaptic plasticity disruption by amyloid beta protein: modulation by potential Alzheimer's disease modifying therapies. Biochem Soc Trans 33:563-567. CrossRef Medline

Salminen A, Kaarniranta K, Haapasalo A, Soininen H, Hiltunen M (2011) AMP-activated protein kinase: a potential player in Alzheimer's disease. J Neurochem 118:460-474. CrossRef Medline

Schmidt EK, Clavarino G, Ceppi M, Pierre P (2009) SUnSET, a nonradioactive method to monitor protein synthesis. Nat Methods 6:275-277. CrossRef Medline

Selkoe DJ (2002) Alzheimer's disease is a synaptic failure. Science 298:789791. CrossRef Medline

Tanzi RE (2005) The synaptic Abeta hypothesis of Alzheimer disease. Nat Neurosci 8:977-979. CrossRef Medline

Tsokas P, Grace EA, Chan P, Ma T, Sealfon SC, Iyengar R, Landau EM, Blitzer RD (2005) Local protein synthesis mediates a rapid increase in dendritic elongation factor $1 \mathrm{~A}$ after induction of late long-term potentiation. J Neurosci 25:5833-5843. CrossRef Medline
Turnley AM, Stapleton D, Mann RJ, Witters LA, Kemp BE, Bartlett PF (1999) Cellular distribution and developmental expression of AMPactivated protein kinase isoforms in mouse central nervous system. J Neurochem 72:1707-1716. Medline

Vingtdeux V, Davies P, Dickson DW, Marambaud P (2011) AMPK is abnormally activated in tangle- and pre-tangle-bearing neurons in Alzheimer's disease and other tauopathies. Acta Neuropathol 121:337-349. CrossRef Medline

Viollet B, Andreelli F, Jørgensen SB, Perrin C, Flamez D, Mu J, Wojtaszewski JF, Schuit FC, Birnbaum M, Richter E, Burcelin R, Vaulont S (2003a) Physiological role of AMP-activated protein kinase (AMPK): insights from knock-out mouse models. Biochem Soc Trans 31:216-219. Medline

Viollet B, Andreelli F, Jørgensen SB, Perrin C, Geloen A, Flamez D, Mu J, Lenzner C, Baud O, Bennoun M, Gomas E, Nicolas G, Wojtaszewski JF, Kahn A, Carling D, Schuit FC, Birnbaum MJ, Richter EA, Burcelin R, Vaulont S (2003b) The AMP-activated protein kinase alpha2 catalytic subunit controls whole-body insulin sensitivity. J Clin Invest 111:91-98. CrossRef Medline 